Document downloaded from:

http://hdl.handle.net/10251/106308

This paper must be cited as:

Fernández-Viñé, MB.; Gómez-Navarro, T.; Capuz-Rizo, SF. (2010). Eco-efficiency in the SMEs of Venezuela. Current status and future perspectives. Journal of Cleaner Production. 18(8):736-746. doi:10.1016/j.jclepro.2009.12.005

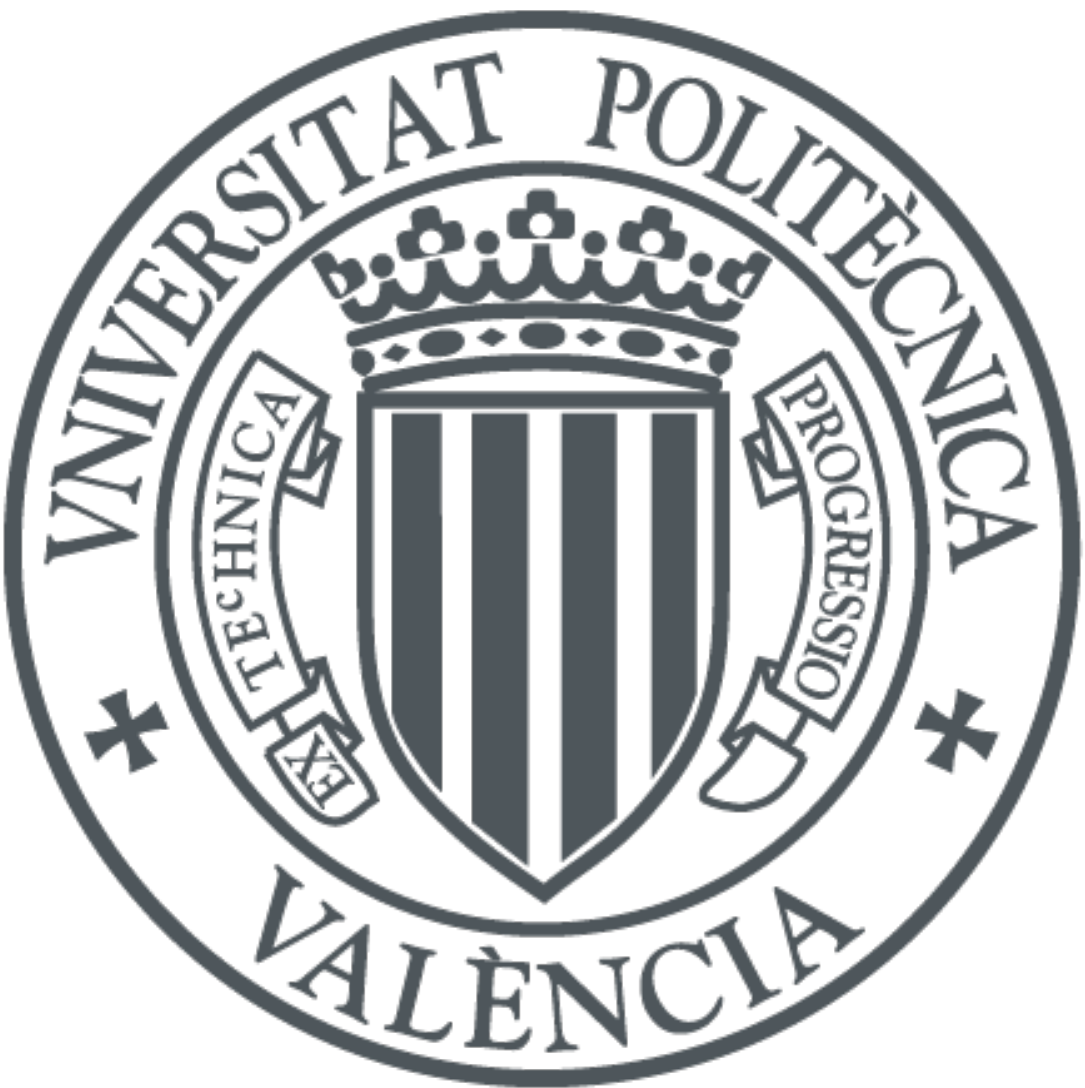

The final publication is available at

http://doi.org/10.1016/j.jclepro.2009.12.005

Copyright Elsevier

Additional Information 


\title{
ECO-EFFICIENCY IN THE SMES OF VENEZUELA. CURRENT STATUS AND FUTURE PERSPECTIVES
}

\author{
María Blanca Fernández-Viñéa, ${ }^{a}$, Tomás Gómez-Navarro ${ }^{b}$, Salvador Capuz-Rizob \\ a Facultad de Ingeniería, Universidad Metropolitana, Terrazas del Ávila, Caracas, Venezuela \\ b Departamento de Proyectos de Ingeniería, Universidad Politécnica de Valencia, Camino de \\ Vera s/n 46022 Valencia, España
}

\section{Abstract.}

This paper presents a comparison analysis of eco-efficiency in the SMEs of Venezuela. The research can be divided into three parts: the first part reviews similar studies in the literature on the level of eco-efficiency exhibited by the companies of Venezuela and other countries. In the second place, the findings of a survey conducted on Venezuelan SMEs allowed the definition of 54 eco-efficiency profiles. Thirdly, six national experts in cleaner production and eco-efficiency were interviewed. The interview was based on a questionnaire similar to that used in the survey of the Venezuelan SMEs. At a second meeting, the experts were asked to discuss the similarities and differences between their answers and those of the company's managers.

The findings of the survey allow us to conclude that Venezuelan SMEs understand the legal environmental regulations that affect them but they do not perceive the influence of external driving forces such as customer demand for green products or institutional incentives. The adoption of eco-efficiency practices is not perceived as an incentive to improve competitiveness and therefore the environmental strategies adopted generally aim at reducing costs or avoiding non-compliance sanctions and negative effects on the company image. Material recycling and re-use, especially packaging materials, are common practices; however, other environmental tools or practices have not been implemented yet, e.g. environmental management systems, process, product and service design tools based on the product life cycle, water or energy reduction, or green marketing. There are also differences among the eight industrial sectors analyzed, food and chemical industries having the highest index of eco-efficiency practices, and plastic and wood industries the lowest.

*Corresponding author. Tel. +58 4142048778 or +58 2126934321 fax: +58 2122403496

E-mail address: mbfernandez@unimet.edu.ve (M.B. Fernández-Viñé) 
Keywords: Eco-efficiency, SMEs, Cleaner Production, Ecodesign, EMS.

\section{Introduction}

SMEs make up most of the industrial activity in Venezuela, as is the case in many other countries. Therefore SMEs generate most of the positive aspects associated with industry development of goods and services, employment, tax payment, etc - but also most of the negative environmental effects, such as consumption of natural resources and emission of pollutants. Unfortunately few statistical data are available that confirm this fact. According to the Instituto Nacional de Estadística de Venezuela, and based on the definition of an SME provided by the European Commission [1], in the year 2003 (latest data available) there were 5,970 industrial companies in Venezuela, 1,592 of which (26.67\%) are medium-size industries, 3,820 (64\%) are small industries and only $9.33 \%$ are large companies [2].

In Venezuela there are $11,172,000$ registered workers, $56.5 \%$ of whom work in the "formal sector" and the rest in the "informal sector" [3]. The informal sector of the economy refers to people that offer their products and services in the streets, do not pay taxes and, in turn, do not enjoy any labour benefits or protection from the administration. Our study focuses on the "formal sector" where $81.5 \%$ of the workers are hired by private enterprises, and $99 \%$ of whom work in SMEs [3].

SMEs are generally family-based and produce for the local (80\%) or regional (15 to $20 \%$ ) markets. Only about 2 to $5 \%$ of SMEs are oriented towards the international market [4]. Moreover, SME technological and efficiency levels are low [5, 6]. Based on a survey conducted in 2007 by the entity that agglomerates all companies, CONINDUSTRIA, during the first quarter the rate of industrial potential employed in medium-size companies was $63.5 \%$, whereas in SMEs it was 54\% [7]. As reported in [7], the reasons for this low productivity are external to industry; in order of importance: political and economic uncertainty, lack of suppliers, difficulties to obtain foreign currency to import materials and supplies (due to the foreign currency exchange regime in Venezuela) and lack of demand. Thus, analysts consider Venezuelan SMEs as "little competitive and of high shut-down risk" [6, 8]. 
In this paper eco-efficiency performance in Venezuelan SMEs is analyzed. The World Business Council for Sustainable Development (WBCSD) in 1991 defined eco-efficiency as "the delivery of competitively priced goods and services that satisfy human needs and bring quality to life, while progressively reducing environmental impacts and resource intensity throughout the life cycle, to a level in line at least with the Earth's carrying capacity" [9]. Several authors defend the idea that eco-efficiency is an opportunity for all enterprises, not only for the largest and more robust ones $[9,10,11,12,13,14,15]$. Furthermore, some studies demonstrate that the projects of Cleaner Production (CP), eco-efficiency and eco-design in developing countries can help SMEs to improve productivity and competitiveness $[16,17,18,19]$.

This research can be divided into three parts: in the first place, similar studies in the literature about the level of eco-efficiency in the industrial companies of Venezuela and other countries are reviewed. In the second place, the findings of a survey conducted on Venezuelan SMEs allowed the definition of 54 eco-efficiency profiles. Thirdly, six national experts in cleaner production and eco-efficiency were interviewed. In this way a comprehensive diagnosis of the level of eco-efficiency in Venezuelan SMEs was obtained.

\section{Eco-efficiency in SMEs.}

The best eco-efficiency practices are generally observed in large and medium sized enterprises. Large companies have a number of advantages: better training, more resources, more visible environmental practices, more incentives and pressure for improving eco-efficiency. However, other studies analyze SMEs that have adopted eco-efficiency practices as a strategy for innovation and change towards a more efficient and competitive production model $[9,10,11$, $12,13,14]$

General studies on eco-efficiency in SMEs can be found in the literature $[20,21,23,24,25,26$, 27]. These studies analyze the driving forces that enhance eco-efficiency in companies and the barriers that hamper the implementation of eco-efficient strategies. The following table summarizes the advantages and disadvantages of SMEs regarding eco-efficiency: 


\begin{tabular}{|l|l|}
\hline ADVANTAGES & DISADVANTAGES \\
\hline Less complex, and more flexible to introduce & $\begin{array}{l}\text { Pollution generation perceived as low. As a } \\
\text { result no budgetary resources invested to } \\
\text { reduce environmental impacts }\end{array}$ \\
\hline More aware of the changes in the market & $\begin{array}{l}\text { Better environmental performance is not } \\
\text { perceived as useful for motivating employees, } \\
\text { increasing benefits } \\
\text { competitiveness improving }\end{array}$ \\
\hline Close relationship with costumers based on & $\begin{array}{l}\text { Not clearly noticeable by the market or public } \\
\text { administration }\end{array}$ \\
\hline Lower dependence on certain stakeholders: & $\begin{array}{l}\text { Insufficient resources to benefit from eco- } \\
\text { efficiency tools. }\end{array}$ \\
\hline shareholders, financial agents, suppliers... & \begin{tabular}{l} 
Reluctant to changes \\
\hline
\end{tabular}
\end{tabular}

Table 1. Advantages and disadvantages of SMEs with respect to eco-efficiency.

Other studies in the literature address the topic of eco-efficiency, eco-design and cleaner production in different regions. These works are comparable in scope and methodology, though they differ in their specific aims:

Van Hemel and Cramer [23] analyzed 77 small and medium manufacturing companies of The Netherlands belonging to the metal, wood, plastic, textile and electronic industrial sectors. The study analyzes SME eco-design barriers and stimuli. Eco-design is an essential eco-efficiency tool. 
Coté et al. [24] carried out a survey on 25 SMEs in Nova Scotia, Canada, in order to measure the levels of eco-efficiency.

Erkko et al. [28] analyzed to what extent Finnish companies with EMAS (Eco-Management and Audit Scheme) statements have added eco-efficiency strategies to their practices. The study is based on the EMAS reports published by 40 companies in the chemical, paper, plastic and metal sectors.

NETREGS is the UK resource for the protection of the environment; it carried out a telephonebased survey of 5,554 SMEs with regard to their environmental management and practices [20, 21].

Capuz-Rizo et al. [25] analyzed the environmental performance of 146 SMEs in the Region of Valencia, Spain.

Vives et al. [29] conducted a comparison analysis in SMEs of different Latin-American countries (Argentina, Brazil, Chile, Colombia, El Salvador, Mexico, Peru and Venezuela) in order to determine the level of implementation of Corporate Social Responsibility (CSR). CSR, among other questions, involves improving the level of eco-efficiency in companies.

Guzmán [30] assessed the level of eco-design in 96 SMEs from the wood sector in Jalisco (México).

The in-depth review of these studies allowed us, on the one hand, to formulate the objectives of the present work and, on the other hand, to compare the results presented in Figure 8

\section{Eco-efficiency in Venezuelan SMEs.}

\subsection{Background.}

No specific studies have been found in the literature that address the topic of eco-efficiency in Venezuelan SMEs. However, related studies $[5,26,31,32]$ report on the loss of competitiveness in Venezuelan SMEs since 1970 from both an economic and environmental point of view. Production has become less and less sustainable and more and more focused on 
local markets, R\&D investment has decreased, and the quality standards of product demand have decreased.

The survey undertaken by the Venezuelan entity "Vitalis" in 2006 [31] reveals that the key factors of the environmental problems in the national industries of Venezuela are:

- Increasing environmental problems in different regions of the country, without due attention from public and private enterprises responsible or the administration.

- Uncontrolled growth of the informal_sector.

- Weak enforcement of actions against non-compliance, in particular by the State Prosecutor and Ombudsman of the Republic.

- Little coordination between environmental and development action plans, neglecting the close relationship that exists between environmental preservation and the quality of life (sustainable development).

- Development of regional, national and supranational infrastructure projects without the corresponding Environmental Impact Assessment (EIA) reports.

- Lack of environmental education and social awareness as well as sparse knowledge of the environmental regulations and norms.

- Inappropriate domestic solid waste disposal and management.

- Poor management of hospital, toxic and hazardous waste materials.

However, according to $[5,26,32]$, Venezuelan SMEs develop their productive activity within a strict environmental legal framework that regulates any industrial activity likely to harm the environment. However, this legal framework is inefficient because of:

- Restricted operational capacity of the national Departments for the Protection of the Environment and lack of definition of the tasks and responsibilities of the environmental departments and agencies.

- Lack of real or apparent definition of the tasks and functions of the public agencies in charge of the protection of the environment.

- No information system or data exchange among public agencies. 
- Duplicity of efforts and functions.

\subsection{Field survey.}

The lack of accurate data available led us to undertake this survey on the level of eco-efficiency demonstrated by the SMEs of Venezuela. The aim of the survey was to know:

- To which extent SMEs are environmentally concerned and how much knowledge they have about the environmental impacts they generate

- Which eco-efficiency tools are implemented in Venezuelan SMEs

- Which driving forces lead to eco-efficiency in SMEs

The main objective of the present work is to know whether the SMEs are adopting the ecoefficiency practices mentioned in the questionnaire, and if so, how and why. In this way the level of eco-efficiency performance in the SMEs surveyed can be evaluated. Additionally, the survey data may help to know what enhances and what hampers eco-efficiency in Venezuelan SMEs To this end, the SME managers were interviewed, using a 35-item questionnaire clustered into 16 topics. The survey sample was defined based on the national classification published by the SME Observatory of Venezuela [4] [33] in 2001 and 2004. The SMEs of the central region of Venezuela were selected for the survey as this area presents a high economic development of the manufacturing industries not directly related to the basic industries (oil and mining): Food, Chemical (not related to oil), Paper, Textile, Construction, Plastic, Metal and Wood. Incomplete and inadequately answered questionnaires were not considered for analysis, giving a total of 54 acceptable samples.

In order to contrast the results obtained in the survey and obtain a more objective view of ecoefficiency performance in Venezuelan SMEs, six national experts in the fields of industry and the environment were interviewed. The experts' profiles are as follows: one expert is a researcher and associate professor in the field of the environment and was given an important national award for his environmental activities. Another is an expert in eco-efficiency and clean production and a member of the "World Network of Clean Production" and the "Clean 
Production Network of the Andres Bello agreement for Latin-America and the Caribbean". The third expert is the President of the environmental NGO VITALIS, a technical consultant of the "World Bank Project-INPARQUES" on environmental education, and the President of the "South-American Water Association (GWP-South-America)". The fourth expert is an industrial consultant in quality and environmental management and advisor of a national agency for the development of innovation and cleaner production methodologies. The fifth expert is the president of a governmental body that steers enterprises towards eco-efficiency and cleaner production. The sixth expert is an honorary member of the "National Academy of Engineering and Habitat", ex-Minister for the Environment and ex-Minister for Civil Works, and ex-president of different world entities related to the environment. The experts were interviewed using a questionnaire similar to that used in the survey on the SMEs

\section{Survey data}

\subsection{General findings.}

The sixteen sections of the questionnaire, corresponding to eco-efficiency practices or tools, are:

- Knowledge or consideration of the environmental aspects of the processes/products

- Green marketing

- Department for the protection of the environment

- Allocation of budgetary resources to minimize pollution

- Personnel training in environmental care

- Use of environmental management systems

- Knowledge of the environmental legal framework

- Pollution control

- Pollution prevention

- Assessment of the environmental impacts of the life cycle of the product 
- Changes in the production process. Reduction of energy and water consumption or selection of renewable resources

- Changes in the production process. Reduction of materials consumption or selection of renewable resources

- Recycling or reuse of materials and waste

- Eco-design practices

- Environmental management of packaging materials

- Maximizing the environmental efficiency of product transportation and delivery

As can be seen in Figure 1, the common eco-efficiency practices adopted by the surveyed companies are "Environmental concern in products/processes", and "Environmental management of packaging materials". However, the experts interviewed did not completely agree with the survey results. The lower index of environmental practices adopted in the SMEs correspond to "Green Marketing", "Department for the Protection of the Environment", "Product Life cycle analysis", "Reduction in Energy consumption" and "Reduction in materials consumption"

The surveyed SMEs usually adopt those environmental practices which are easy to implement, involve little time or financial investment, and produce short-term, visible and predictable benefits. This consideration coincides with the phenomenon reported in the studies of Spain [25], Canada [24] and Holland [23], known as "picking the low hanging fruits".

To analyze the level of eco-performance of each industrial sector, in the graph of Figure 1, the $\mathrm{Y}$-axis shows the number of companies that claimed to adopt practices in the 16 eco-efficiency items of the questionnaire. The Food sector presents the highest index of companies that claim to adopt eco-efficiency practices, followed in decreasing order, by the Chemical, Textile, Metal, Paper, Construction, Plastic and Wood sectors. 


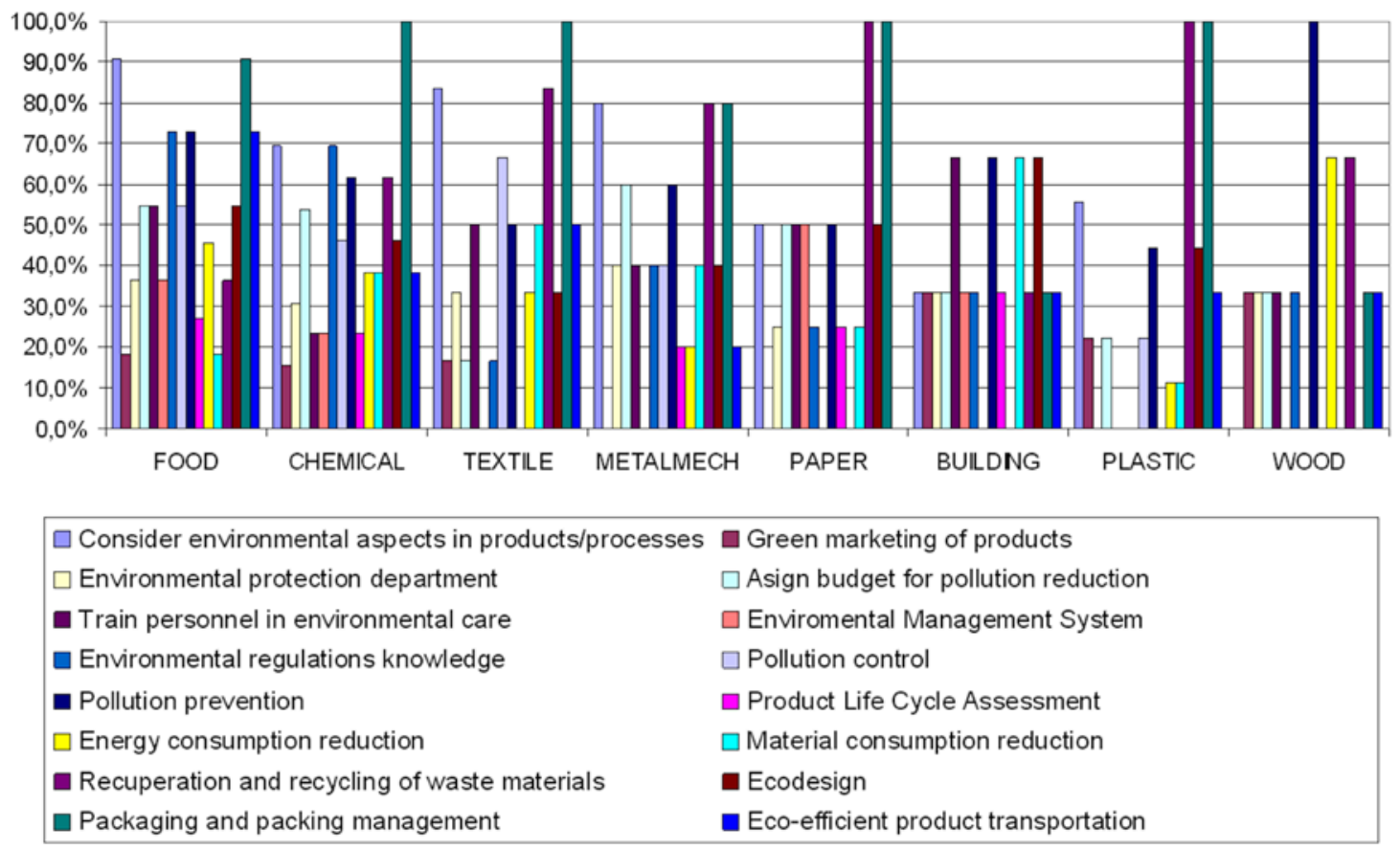

Fig. 1. Percentage by industrial sector and eco-efficiency item

In general, the level of eco-efficiency in SMEs is low. Even the most eco-efficient sector, i.e. the Food sector, presents rates lower than $50 \%$ in seven eco-efficiency items. That is, less than half of the surveyed companies claim to adopt eco-efficiency practices

\subsection{Partial findings of the survey}

Hereafter are the data obtained from the questionnaire conducted on the Venezuelan SMEs:

- Consider environmental aspects of products/processes

A total of $67 \%$ surveyed companies claim to take into consideration the environmental aspects of their products and processes. However, the answers to the questions of how they develop the corresponding actions, contradict this statement.

Those companies that answered affirmatively were asked for their reasons. Most of them claim to be "Environmentally concerned" (58.3\%), 50\% mention "Legal mandatory requirements" (50\%), 33.3\% "Market demands", and 33.3\% "Cost reductions" (See Figure 2). Market pressure 
has a small influence, in terms of customer demands, competitors or company image. This conclusion is consistent with the results for other items, which reveals that market pressure is not an Eco-efficiency driving force in Venezuela

\section{DO SME CONSIDER THE ENVIRONMENTAL ASPECTS OF THEIR PRODUCTS AND PROCESSES?}

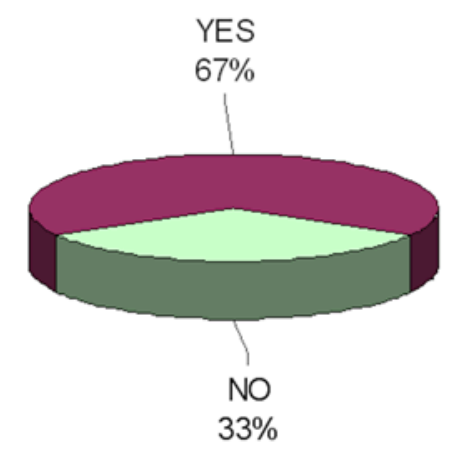

IF YES, WHY?

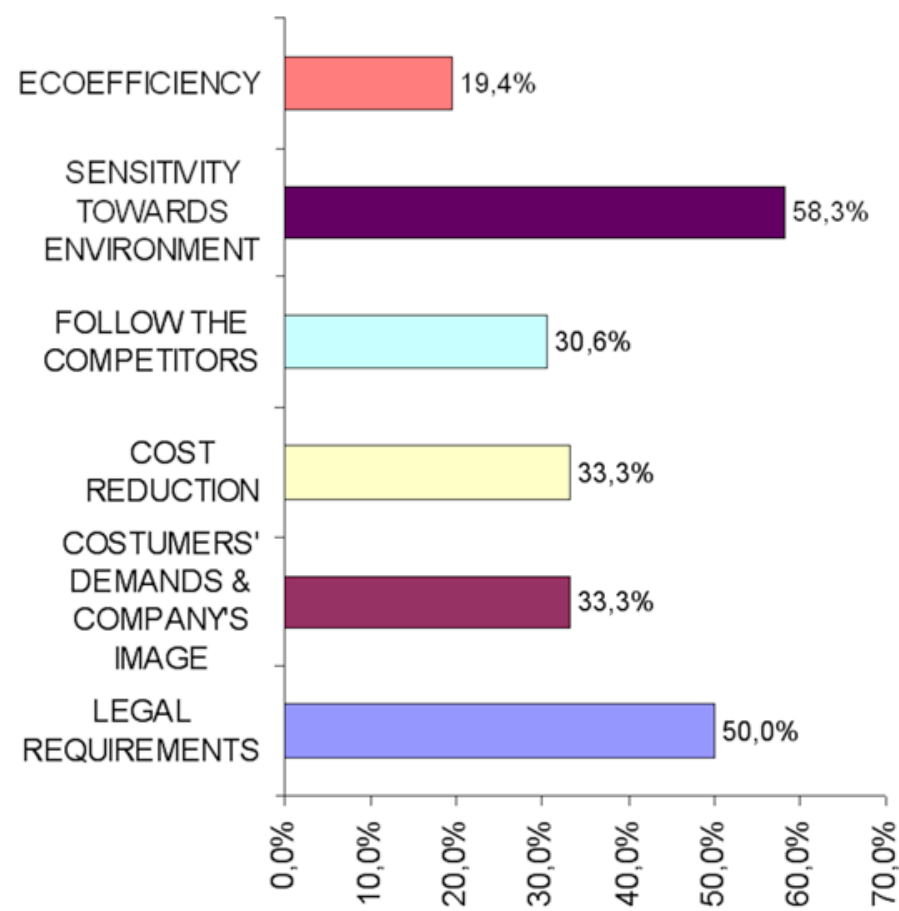

Fig. 2. Reasons for considering Environmental issues

\section{- Green Marketing}

A total of $83 \%$ SMEs do not consider the environment in their marketing strategies. In practice, when the companies claim to be sensitive to environmental issues their concern does not focus on environmental preservation and protection but on avoiding negative effects on their product or service. SMEs tend to avoid harming their product image and sales, or administrative penalties, but they do not tend to promote a green image.

- Department for the Protection of the Environment 
About $72 \%$ SMEs do not allocate budgetary resources to the protection of the environment; $15 \%$ SMEs have one person in charge of environmental issues and only $4 \%$ of SMEs have a Department for the Protection of the Environment. This result confirms the perception that environmental concern is not proactive or permanent in SMEs. Rather it is triggered by isolated actions to comply with mandatory requirements.

- Allocate resources to reduce pollution

A total of $57 \%$ SMEs do not allocate any budgetary resources to reduce pollution; $20 \%$ invest less than $0.1 \%$ of their sales income; only $8 \%$ allocate more than $1 \%$ of their sales income to reduce pollution of their products and production processes. These results clearly indicate the low importance attached by SMEs to eco-efficient practices

- Application of Environmental Management Systems and Tools

About $7 \%$ of SMEs apply some Environmental Management System (EMS) according to ISO standard 14,000; 11\% apply a self-developed EMS and 82\% have no EMS system or tool. The SMEs that have implemented an EMS system generally operate with large companies that require their suppliers to apply EMS tools.

- Training personnel in environmental care

About $35 \%$ of SMEs claim that their personnel have been trained in environmental issues. This answer combined with previous ones indicates that SMEs allocate few resources to environmental control actions.

- Knowledge of environmental regulations

Venezuelan SMEs know the regulations that may directly affect them. In general, $75 \%$ claim to know which are the hazardous substances used in their products and processes; $50 \%$ undergo periodical supervisions. However, less than half of the SMEs (42.6\%) claim to maintain an updated database of environmental legislation. Generally SMEs are only concerned with those norms liable to cause non-compliance sanctions, but are not interested in those norms which may benefit them. That is to say, they do not know the environmental regulations that may involve incentives, access to subsidies, market opportunities, etc. 
- Pollution Prevention and Control

Surprisingly, $48 \%$ of the surveyed SMEs claim to prevent pollution, $24 \%$ control pollution and $13 \%$ adopt both practices. Only 15\% admit that they neither control nor prevent pollution. However, as shown in Figure 3, 55.6\% of SMEs do not measure their levels of pollution and $11 \%$ say that they do not emit any kind of pollutants. Of the $34.3 \%$ of SMEs that measure the emission of pollutants, $9.3 \%$ do it on an annual basis, $6 \%$ every six months and $19 \%$ more frequently. Pollution cannot be properly controlled or prevented unless the levels of pollution are measured on a regular basis, therefore the results from both questions are contradictory. The number of companies that prevent and/or control pollution is inconsistent with the questions above and below in the questionnaire. This reveals certain a misunderstanding of the concept of pollution control and prevention. SMEs are also reluctant to admit that they do not properly manage environmental issues.

\section{MEASURING CONTAMINANT SUBSTANCES}

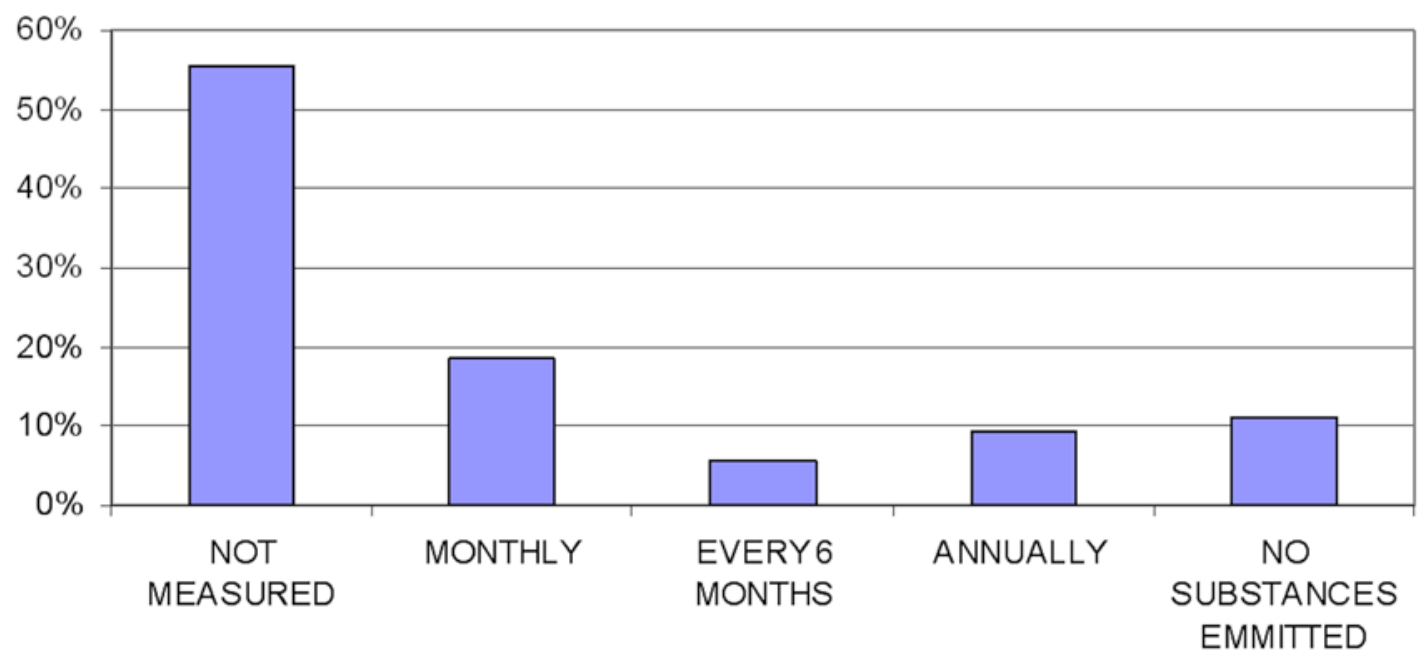

Fig. 3. Frequency of measurement of contaminant substances

\section{- Environmental Impact Assessment of Product Life Cycle}

Only $17 \%$ of SMEs responded positively to this item. Most SME managers did not know the concept of Product Life Cycle and were given additional explanations during the interviews. 
- Modify the Production Process. Reduce Energy and Water Consumption or Select Renewable resources. Reduce materials consumption or Select Low Impact Resources

A total of $11.1 \%$ of SMEs do not adopt any of these practices. Among those SMEs that adopt one or more practices, $60 \%$ recycle or reuse materials (see Figure 4 ); $33 \%$ reduce energy consumption, $33 \%$ reduce water consumption, and $33 \%$ reduce materials consumption. Very few SMEs select renewable resources or try to reduce the emissions of polluting substances. The conclusion is that the environmental practices implemented in the SMEs are closely related to short-term economic benefits.

\section{MODIFICATION OF THE PRODUCTION PROCESS}

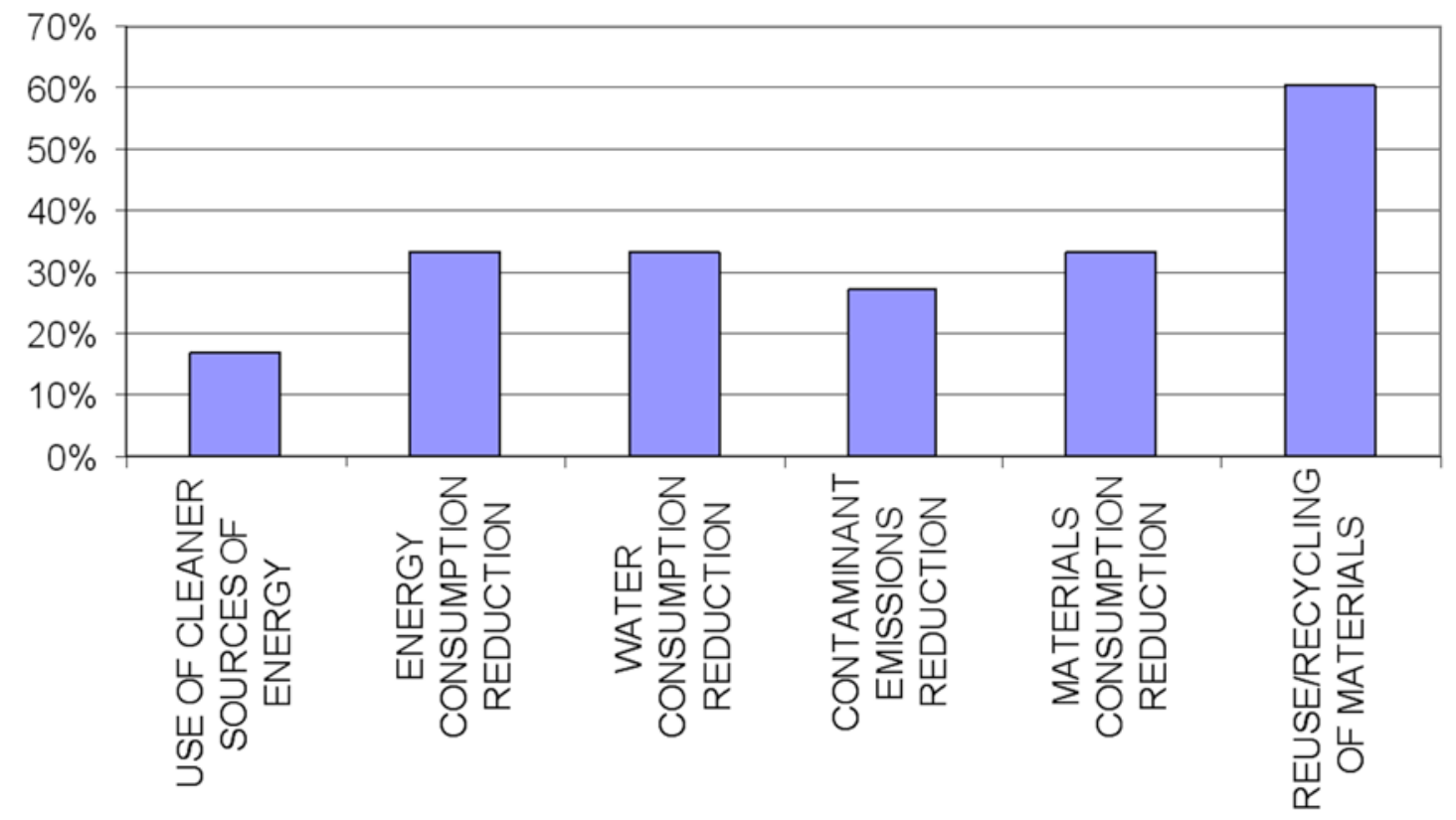

Figure 4. Answers to the question "Which changes in the Production Processes lead to environmental improvements?"

\section{- Waste Recycling or Reuse}

With regard to waste management, $31 \%$ of SMEs use recycled raw materials, $28 \%$ recover defective products, $14 \%$ recycle their waste and $22 \%$ do not undertake any action (see Figure 5). In Venezuela, as in many other developing countries, there is an important market of 
recycled raw materials (especially packaging materials), due to the very low cost of the workforce (mostly from the informal sector) and the relatively high prices of raw materials. In developed countries, however, the situation is the opposite and selective waste disposal and recycling is subsidized by the government or discouraged through taxes on waste generation.

WASTE MANAGEMENT

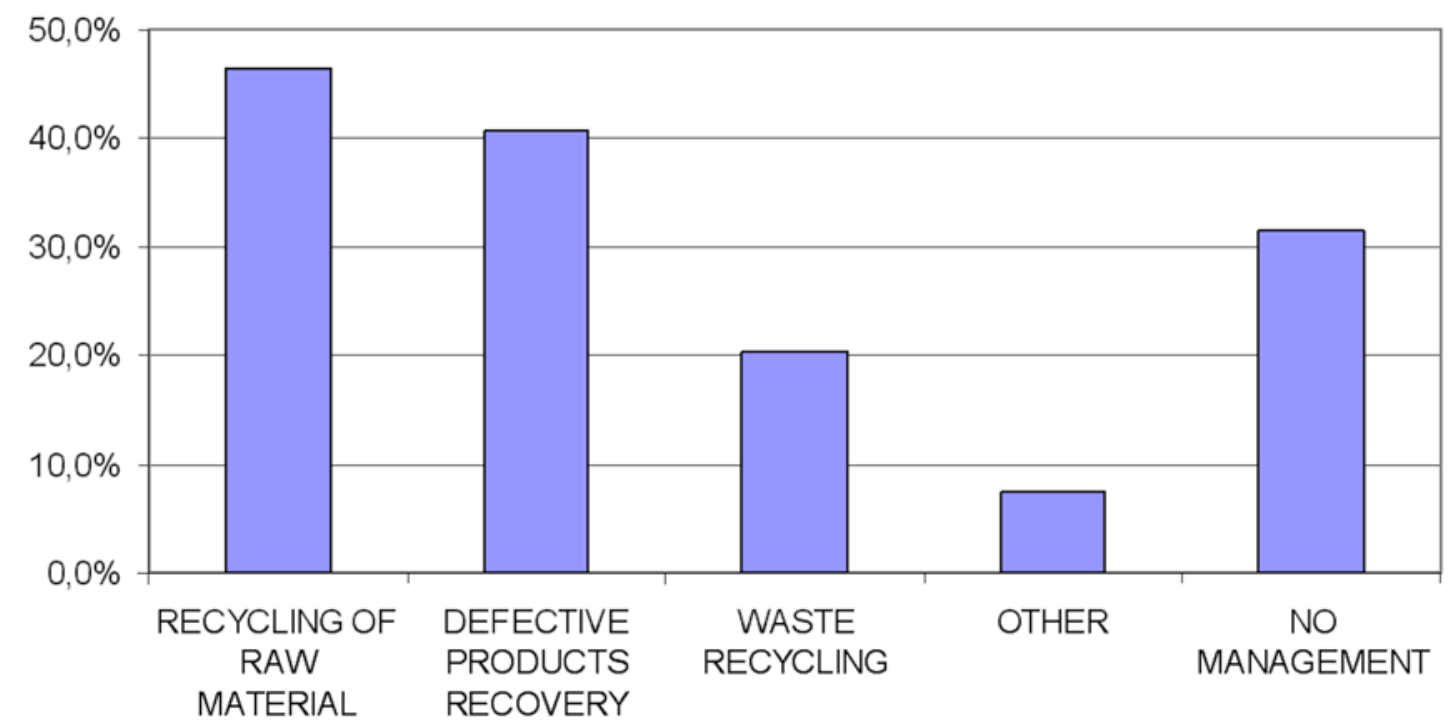

Figure 5. Answers to the question "Is the generated waste recovered or recycled for reuse as raw material in manufacturing or production processes?

-Eco-design

Similarly, many SMEs say that they adopt eco-design practices (44\% vs. $56 \%$ which answer this question negatively). But in practice, they adopt restricted eco-design practices (see Figure 6) not based on Product Life Cycle analysis or on environmental impact assessment 

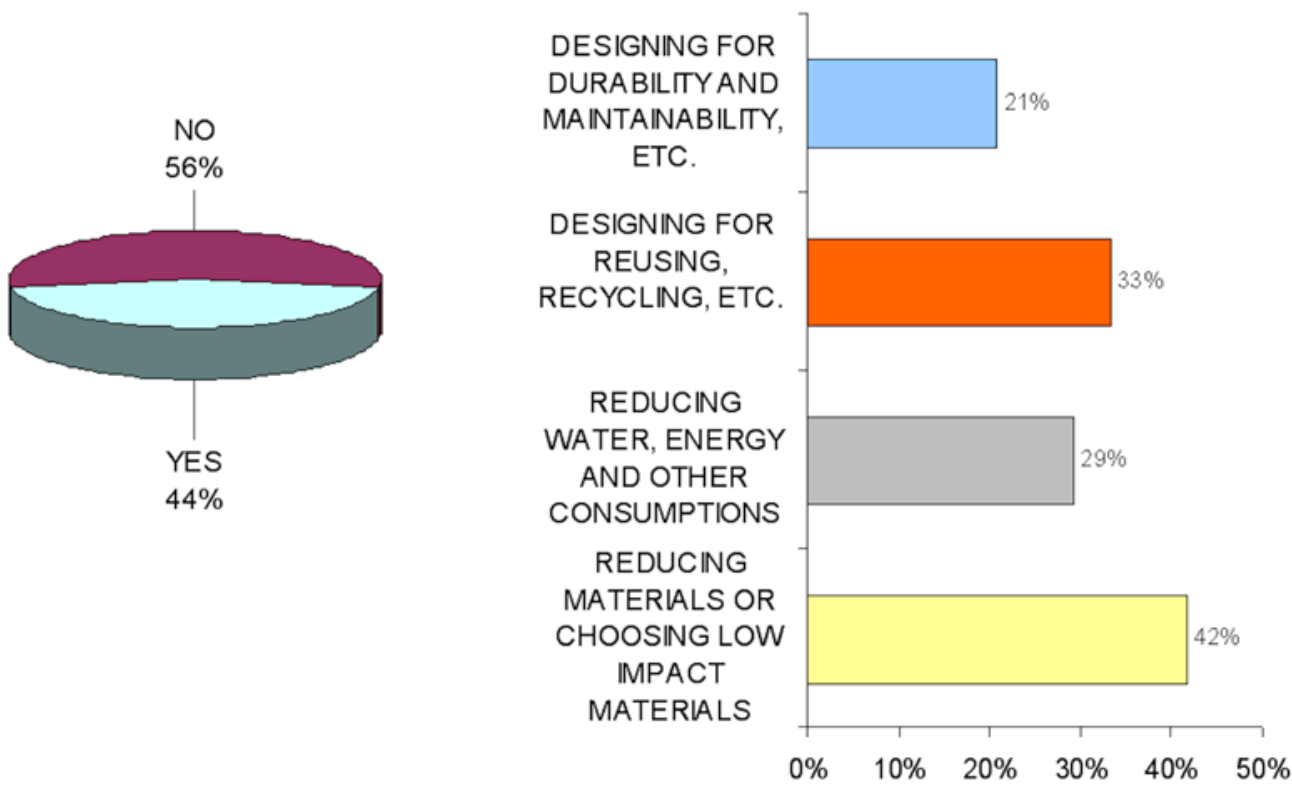

Figure 6. SME Eco-design practices

- Environmental Management of Packaging materials

A total of $93 \%$ of SMEs claim to adopt practices to reduce environmental impacts from packaging. Thus, $46 \%$ use recyclable packaging, 35\% reusable packaging, $14 \%$ clean packaging and 5\% packaging with added value for users. The reason for this is the existence of a recyclable-packaging market, but is not due to environmental concern or awareness

- Maximize environmental efficiency of product transportation and delivery

A total of $41 \%$ of SMEs manage the transportation of their products with environmental concern. However, the answers reveal that the complexity of this process is not fully understood. The managers surveyed usually refer to vehicle maintenance rather than to route planning, vehicle load optimization, etc.

\subsection{A comparison analysis with the experts' answers.}


As mentioned above, six experts in the fields of industry and the environment were interviewed using a questionnaire similar to the one used in the survey of the SMEs, though adapted so that the experts could estimate the percentage of SMEs that implement each environmental item of the questionnaire. Figure 7 shows the comparison of the data. The radial lines represent the number of SMEs that adopt Eco-efficiency practices. The lines also show the average rates of the experts' estimations. For example, the radial line of eco-design shows that $44 \%$ of SMEs claim to adopt eco-design practices but the experts estimate that only $10 \%$ of SMEs actually do so.

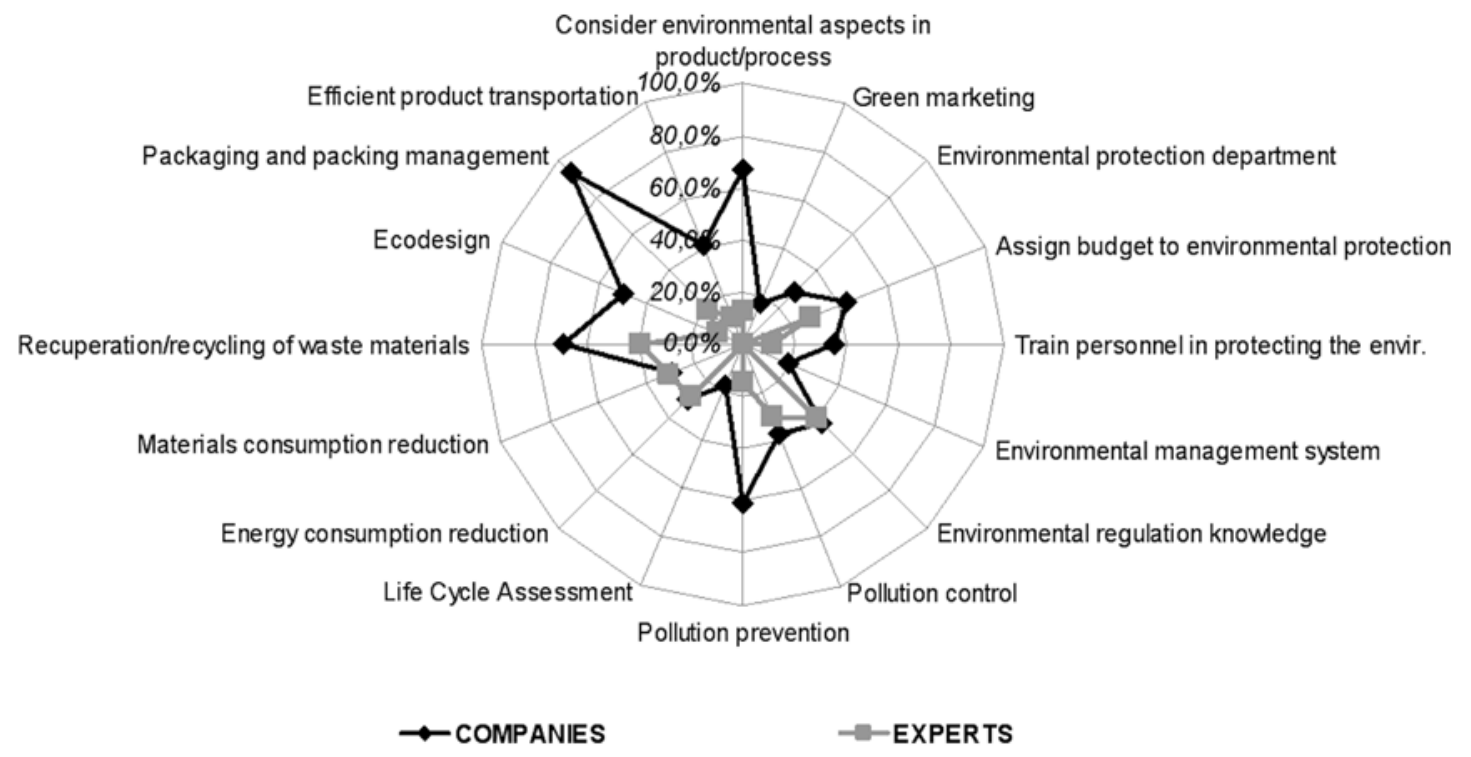

Figure 7. Comparison graph of the SMEs and the Experts' opinion

The experts' opinion is significantly more critical, with lower rates than those obtained in the SME survey. This is partially due to the fact that the experts' opinion is not affected by managerial strategies and policies, and partly because they have a full understanding of the items of the survey. Of the 16 comparison axes, there are coincidences in issues such as "Knowledge of the environmental regulations", "Reduction of energy and water consumption or selection of renewable resources", "Reduction of materials consumption or selection of low 
impact resources" and "Pollution control". More differences are observed in all other issues, especially in "Pollution prevention", "Packaging management", "Eco-design", and "Environmental concern in products/processes"

At a second meeting, the experts were asked about the differences between their estimations and those of the SME managers. The experts' opinions can be summarized as follows:

The SMEs consider that "Environmental improvement of products and processes" or "Pollution prevention and control" mean to comply with environmental regulations. A company will not easily acknowledge its non-compliance with mandatory regulations and therefore will tend to claim that it improves its products and services so as not to be under legal suspicion. Anyway, their environmental objectives and goals hardly ever go beyond the mandatory requirements of environmental regulations.

Those environmental actions not regulated by law are aimed at reducing costs and avoiding sanctions or damage to the company image.

SMEs claim to take environmental issues into consideration regarding their products and production processes, though these actions are not undertaken with rigor or comprehensively. They have no feedback on the effects of their actions, partly because they are not considered relevant and partly because there is no feedback. As a result of this, companies are neither aware of their environmental impact nor of their contribution to sustainable development, nor of the demand for cleaner products and services. They are also unaware of the existence of more eco-efficient alternative technologies or services, or of subsidies and incentives from the administration to improve eco-efficiency.

Consequently, training of personnel and resource allocation to environmental management are restricted to compliance with the mandatory norms. The strategy followed is to minimize costs and changes in the production process. Environmental protection does not form part of the competitive or managerial strategies and policies of the company

Generally, if a partial or isolated practice is adopted, it is as if a complete and comprehensive action had been undertaken. That is the case for packaging management. Only profitable 
packaging materials are eco-managed, and often because of suggestions from people outside the company, in the informal sector. Similarly, regarding eco-design, any minor action is considered as an eco-design practice, even if it is not based on any known eco-design model or tool (e.g. LCA)

\section{Comparison analysis of similar studies conducted in other countries.}

The literature was reviewed to compare the results of similar surveys conducted in other countries. The comparison criteria used are the same as the items of our survey on SMEs EcoEfficiency (see Figure 8). The table presents the studies with sufficient, accurate (or sufficiently accurate?) data for the comparison analysis. The rest of the studies were used in the general comments. The cells show a qualitative scale for Figure 9, depending on the survey data. 


\begin{tabular}{|c|c|c|c|c|c|c|}
\hline ACTIONS $\downarrow \quad$ SURVEYS - & $\begin{array}{c}\text { THE } \\
\text { NETHERLANDS }\end{array}$ & FINLAND & UNITED KINGDOM & VALENCIA (SPAIN) & VENEZUELA & JALISCO (MÉXICO) \\
\hline $\begin{array}{l}\text { CONSIDER ENMRONMENT IN } \\
\text { PRODUC TSIPROCESSES }\end{array}$ & NOT STUdied & $\mathrm{HIGH}$ & $\mathrm{HIGH}$ & MEDIUM & LOW & MEDIUM \\
\hline ENVIRONMENTAL MARKETING & $\mathrm{HIGH}$ & NOT STUDIED & MEDIUM & LOW & VERY LOW & NOT STUDIED \\
\hline $\begin{array}{l}\text { ENVIRONMENTAL } \\
\text { DEPARTMENT }\end{array}$ & NOT STUDIED & NOT STUDIED & MEDIUM & Low & VERY LOW & LOW \\
\hline $\begin{array}{l}\text { BUDGET ASSIGNED TO } \\
\text { ENMRONMENT }\end{array}$ & NOT STUDIED & NOT STUDIED & NOT STUDIED & MEDIUM & LOW & LOW \\
\hline IRAINING IN ENMRONMENT & Not STUdied & NOT STUdied & Not StUdied & LOW & LOW & MEDIUM \\
\hline $\begin{array}{l}\text { ENVIRONMENTAL } \\
\text { MANAGEMENT SYSTEM }\end{array}$ & NOT STUDIED & NOT STUDIED & Low & VERY LOW & VERY LOW & VERY LOW \\
\hline $\begin{array}{l}\text { ENVIRONMENTAL } \\
\text { REGULATION KNOMLEDGE }\end{array}$ & $\mathrm{HIGH}$ & NOT STUDIED & VERY LOW & LOW & MEDIUM & MEDIUM \\
\hline POLLUTION CONTROL & NOT STUDIED & MEDIUM & NOT STUdED & $\mathrm{HIGH}$ & LOW & LOW \\
\hline POLLUTION PREVENTION & MEDIUM & Low & NOT STUDIED & VERY LOW & Low & NOT STUDIED \\
\hline LIFE CYCLE ASSESSMENT & NOT STUDIED & VERY LOW & NOT STUDIED & VERY LOW & VERY LOW & NOT STUDIEO \\
\hline $\begin{array}{l}\text { ENERGY CONSUMPIION } \\
\text { REDUCTION }\end{array}$ & $\mathrm{HIGH}$ & $\mathrm{HIGH}$ & VERY LOW & HIGH & LOW & NOT STUDIED \\
\hline $\begin{array}{l}\text { MAIERIAL CONSUMPTION } \\
\text { REDUC TION }\end{array}$ & $\mathrm{HIGH}$ & LOW & NOT STUDIED & $\mathrm{HIGH}$ & MEDIUM & NOT STUDIED \\
\hline $\begin{array}{l}\text { RECUPERATION AND } \\
\text { RECYCLING OF WASTE } \\
\text { MATERIALS }\end{array}$ & $\mathrm{HIGH}$ & MEDIUM & MEDIUM & $\mathrm{HIGH}$ & $\mathrm{HIGH}$ & MEDIUM \\
\hline ECODESIGN & VERY LOW & NOT STUDIED & NOT STUDIED & LOW & VERY LOW & VERY LOW \\
\hline $\begin{array}{l}\text { PACKAGING AND PACKING } \\
\text { MANAGEMENT }\end{array}$ & MEDIUM & NOT STUDIED & NOT STUDIED & $\mathrm{HIGH}$ & MEDIUM & LOW \\
\hline EFFICIENCYIN TRANSPORT & NOT STUDIED & NOT STUDIED & Not STUdied & MEDIUM & VERY LOW & MEDIUM \\
\hline
\end{tabular}

Figure 8. Comparison analysis of Eco-efficiency performance in different countries 


\begin{tabular}{|c|c|}
\hline \% OF COMPANIES & QUALITATIVE SCALE \\
\hline $\mathbf{8 0 - 1 0 0 \%}$ & VERY HIGH \\
\hline $60-79 \%$ & HIGH \\
\hline $40-59 \%$ & MEDIUM \\
\hline $20-39 \%$ & LOW \\
\hline $1-19 \%$ & VERY LOW \\
\hline $0 \%$ & NOT STUDIED \\
\hline
\end{tabular}

Figure 9. Qualitative scale used in Figure 8.

\subsection{Discussion of results.}

Firstly, it is important to note the wide range of companies, as well as the processes and products, analyzed. Bearing this in mind, the results and conclusions of the analysis can only be indicative. However, these indicative conclusions can help us to gain a better understanding of eco-efficiency performance in SMEs.

The surveys analyzed reveal that environmental concern and adoption of structured and comprehensive green practices depend on company size, i.e. the larger the company, the higher the level of eco-efficiency.

Similarly, there are differences in eco-efficiency performance among the industry sectors of a country. The surveys show that certain industrial sectors present higher levels of eco-efficiency than others. In Venezuela the industrial sectors with the highest index of eco-efficiency are the Food and Chemical industries (excluding the national oil extraction and processing-industry). And the lowest eco-efficiency levels correspond to the Plastic and Wood sectors. 
Most surveys distinguish between internal and external driving forces (DFs) or stimuli for ecoefficiency. Internal DFs are generated inside the company: increasing profits, environmental awareness of employees and managers, innovation opportunities, improvement of company image, etc. External DFs are generated outside the company: environmental legislation, competitors' actions, action in the supply chain (suppliers and customers), customer demands, etc. In the surveys of the developed countries or regions, eco-efficiency DFs are both internal and external. However, in developing countries there are few internal DFs and only regulations and customer demands stimulate SMEs to improve eco-efficiency. The high index of SMEs that claim to be "environmentally concerned" is motivated by managers' responses rather than by any real action from the SMEs. That is to say, even if awareness exists, this is not the main reason for the adoption of eco-efficient practices in SMEs. This result is similar in other surveys, such as Van Hemel and Cramer [23].

On average, few companies take into consideration environmental issues in their products and processes. In Venezuelan SMEs, this is also the case, a situation that can be explained by the acute social problems that exist in the country whereby eco-efficiency is not seen as a priority strategy or goal. Although market pressure is an influential external DF, the adoption of Green Marketing practices is scarce in the industries of the surveys analyzed, except in Holland. In Venezuela, SMEs also show a limited adoption of Green Marketing strategies.

Actions concerning environmental management in companies (environment protection department, budgetary allocation to environmental actions, training of personnel and environmental management systems) get a low or very low rating in the surveys that analyze this issue. In Venezuela there is also a limited application of environmental management systems and tools.

The different surveys also indicate limited adoption of eco-design strategies in SMEs. Ecoefficiency activities focus on production processes rather than on products. This situation is changing in Europe with the "new environmental approaches" but no changes are expected in the short-term in Latin-America unless more manufactured products are exported. 
It is worth noting that, except in the surveys of Holland, Venezuela and Mexico, the rest of the studies report little or very little knowledge of environmental regulations.

Companies do not apply Life Cycle Assessment tools, i.e. this valuable tool is restricted to the academic community and large companies.

Reductions in Energy and materials consumption are the most common practices adopted by the companies analyzed in the surveys. These actions seem more motivated by cost savings than by environmental concern. This trend is less noticeable in Venezuela because energy is cheap due to the abundance of energy resources, nationalization of the resources and low fuelprice policies.

In developed countries waste/materials recycling and recovery is legally regulated and mandatory (rather than triggered by environmental concern) through automated infrastructures and financed by the companies. In Latin-American countries, recycling is a profitable business that saves companies raw material expenses, and is based on the workforce rather than on automation.

With regard to efficient environmental management of product transportation, the experts claim that product transportation is through safer rather than more efficient routes. This is due to the very low price of fuel and the high level of insecurity existing in Venezuela

\section{Conclusions}

In addition to the partial findings mentioned above, this research presents the following conclusions. First, the data of the survey could be considered optimistic. Generally the companies that answered the questionnaire are companies that adopt green practices or are environmentally concerned. The companies not concerned with the environment or aware of their negative environmental behaviour try not to get involved in surveys of this kind.

Regarding the questionnaire, when the questions refer to unknown concepts, the respondents didn't always acknowledge their lack of knowledge. They tended to respond in a way that they believed would reflect positively upon the company image. There is greater agreement on those 
environmental items which are fully understood by experts and respondents. However, there are more inconsistencies with regard to the more complex issues.

Venezuelan SMEs do not perceive their own environmental impacts as significant and therefore no resources are allocated to reduce environmental impact. SMEs do not believe that a better environmental performance can help them increase sales, improve competitiveness or motivate employees

SMEs tend to be reluctant to make changes, and reactive rather than proactive about environmental issues. SME environmental goals usually tend to reduce direct costs and to avoid non-compliance sanctions or damage to the company image. Therefore, few companies apply environmental management systems or eco-efficiency tools. They have insufficient resources to benefit from eco-efficiency tools.

Eco-efficiency driving forces are similar in all regions, particularly market pressure and governmental intervention in the form of economic taxes or legal requirements. Environmental regulation is similar in all the countries analyzed. However, the level of influence depends on the nature of the enforcement regimes rather than on knowledge of the regulations. In Venezuela there are no efficient enforcement mechanisms to control an SME's compliance with environmental regulations and thus it is not a very important stimulus, despite being the most influential DF. On the other hand, if the SMEs of countries with weak enforcement regimes export their products to countries with tighter environmental regulations, this can enhance the implementation of green actions. Unfortunately, Venezuelan SMEs export very few products.

In countries with a degraded environment, local public opinion and global pressure are highly influential. In Latin-American countries, particularly in Venezuela, with a less degraded environment, global campaigns for the protection of the environment do not find the same echo. Because of this, and because of the acute social problems affecting the country, the protection of the environment is not seen as significant a factor as in developed countries Finally, based on the responses of the experts and the reviewed studies, certain proposals can be defined for enhancing eco-efficiency in Venezuelan SMEs. Among the stakeholders that can 
motivate Venezuelan SMEs to adopt eco-efficiency practices, customers and unions generally do not demand green products. Green associations and mass media are only influential in the case of important threatening environmental impacts caused by large companies, but they do not care about SME eco-efficiency. Product supply chains (both customers and suppliers) and competitors generally have similar low levels of eco-efficiency. Therefore, the only stakeholders that exert some influence and are effectively enhancing the adoption of eco-efficiency are business associations and public administrations.

In Venezuela, as a result of its political situation, public administration (PA) is the only stakeholder with the capacity and responsibility to assume leadership in the promotion of ecoefficiency in SMEs. Leadership thus comes not only from public administrations but also from market pressure through nationalized companies. The PA has environmental management tools such as: protection of natural spaces and species, demand for green products and services, training and awareness campaigns, price policies (taxes, subsidies, etc) and command and control legislation.

The level of protection of natural spaces is high in Venezuela. As already mentioned, environmental legislation and norms are very strict, but there are no formal enforcement mechanisms. In this respect, in addition to higher sanctions and control, more support and information from public administrations to SMEs could enhance eco-efficiency.

Another proposal might be the development of instruments for a better pricing policy, redistributing taxes and subsidizing green products to improve SME competitiveness.

Public administrations can also influence the market. According to our calculations, Venezuelan administrations and nationalized companies constitute more than $60 \%$ of the market. Under such conditions, a policy of green products has enormous potential. Environmental assessment criteria should be included in tendering and supplier selection processes for the administration. This could generate a greater demand for green products and services and boost ecoefficiency. 
Incentive mechanisms for the adoption of environmental protection practices already implemented in developed countries could also contribute to the development of a more ecoefficient market. For example, reliable information mechanisms for users (eco-labels), awareness-raising campaigns through publicity, environmental education and training of citizens and professionals.

Practically none of these proposals have been implemented in Venezuela. However, the experts coincide in claiming that they could raise social awareness in environmental issues, stimulate green marketing and facilitate the access of SMEs with eco-efficient products to subsidies and credits.

\section{References}

[1] European Commission. COMMISSION RECOMMENDATION of 6 May 2003 concerning the definition of micro, small and medium-sized enterprises (notified under document number C(2003) 1422) (2003/361/EC). Official Journal of the European Union, 2003.

[2] Instituto Nacional de Estadística. Estadísticas Económicas, 2003. Downloaded from. http://www.ine.gob.ve/industria/Indus Man 2003.htm, (10.2.2006)

[3] Instituto Nacional de Estadística. Estadísticas Económicas, 2007. Downloaded from. http://www.ine.gob.ve/tripticos/IndicadoresEconomicos/C1IndicEcon.asp?periodo=200701, (12.3.2007).

[4] Páez T, Rodríguez B, Itriago D, Cuárez M. Observatorio PyMEs y nuevas tendencias de la información y la comunicación. Caracas: Ceatpro, 2004.

[5] Mendoza J Villegas A. La producción más limpia y el consumo sustentable en Venezuela. Ministerio del Ambiente y los Recursos Naturales. Dirección General de Calidad Ambiental, Caracas: Fondo Editorial Fondoambiente, 2004.

[6] Viana H, Cervilla M. A Model for the Empirical Analysis of Technological Capabilities of Manufacturing Firms. Management of Engineering and Technology, PICMET'99 1999; 1:310325. 
[7] Conindustria. Encuesta de coyuntura trimestral Situación IV trimestre 2006-Perspectivas I trimestre 2007. Downloaded from.

http://www.conindustria.org/web2005/coninceel/BoletCoyuntura76.pdf, (6.5.2007).

[8] Fuster J. Evaluación Final del Programa Coninpyme Informe para Banco Interamericano de Desarrollo. (ATM/ME-5942 /VE). ACE, 2004.

[9] UNEP-WBCSD. Cleaner production and Eco-efficiency: from ideas to action. Geneve: UNEP, 1998.

[10] Gómez-Navarro T. Propuesta metodológica para la mejora de la ecoeficiencia de los productos industriales a lo largo de su ciclo de vida. Aplicación a las PYME de la Comunidad Valenciana. Tesis Doctoral. Valencia: Universidad Politécnica de Valencia, 2004.

[11] Safari I. Economical Efficiency with Ecological Efficiency, Incorporating Eco-efficiency at SMEs. Finland: Turku Polytechnic, 2005. Downloaded from. www.vito.be/erscp2005/documents/papers/PAPER086.PDF, (1.5.2008).

[12] UEAPME. Overview of the problems faced by micro and small businesses when applying the concept of eco-efficiency, including energy efficiency. 2007. Downloaded from. www.ueapme.com/docs/pos papers/2007/0710 Guido problems SME.pdf, (23.2.2008).

[13] Woolman T, Veshagh A. Designing Support for Manufacturing SMEs Approaching Ecodesign and Cleaner Production. Learning from UK Survey Results. Warwick, UK: Warwick Manufacturing Group. University of Warwick, 2007

[14] Vernon J, Stephen E, Pinder D, Kaja C. The greening of tourism micro-business: Outcomes of focus group investigations in South East Cornwall. Business Strategy and the Environment 2003;12:49-69.

[15] van Berkel R. Cleaner production and eco-efficiency initiatives in Western Australia 19962004. Journal of Cleaner Production 2006;15(8-9):741-55.

[16] Ciccozzi E, Checkenya R, Rodriguez AV. Recent experiences and challenges in promoting cleaner production investments in developing countries. Journal of Cleaner Production 2003;11(6):629-38. 
[17] Byung-Wook L, Seung-Tae J, Jeong-Heui, K. Environmental Accounting Guidelines and Corporate Cases in Korea. Implications for Developing Countries. In: Implementing Environmental Management Accounting: Status and Challenges. Springer Netherlands, 2006: 239-55.

[18] HILSON G. Eco-efficiency: Improving environmental management strategy in the primary extraction industry. Journal of Environmental Systems 2002-200;29(1):1-14.

[19] Sangwon S, Kun Mo L, Sangsun H. Eco-efficiency for Pollution Prevention in Small to Medium-Sized Enterprises: A Case from South Korea. Journal of Industrial Ecology 2008;9(4): 223-40.

[20] Netregs. SME-nvironment 2005: England. A review of changing environmental attitudes and behaviours among small and medium-sized businesses in England. Downloaded from. http://www.netregs.gov.uk/netregs/1169119/?lang= e, (1.10.2006).

[21] Netregs. SME-nvironment, A review of changing environmental attitudes and behaviors among small and medium sized business in the UK. 2005. Downloaded from. http://www.netregs.gov.uk/comillonesondata/acrobat/2005 uk sumillonesary 1197319.pdf,

[22] Vettori A. SMEs \& Environmental Policy. EURADA. Dirección General de la Comisión Europea para el Ambiente, 2007. Downloaded from. www.eurada.org/doc/EU\%20Policy\%20Update/Andrea\%20Vettori.ppt, (2.5.2008).

[23] van Hemel C, Cramer J. Barriers and stimuli for ecodesign in SMEs. Journal of Cleaner Production 2002;10:439-53.

[24] Coté R, Booth A, Louis B. Eco-efficiency and SMEs in Nova Scotia, Canada. Journal of Cleaner Production 2006;14: 542-50.

[25] Capuz S, Gómez T, Viñoles R, López R, Bastante M, Vivancos J, Ferrer P. Situación actual y perspectivas del Ecodiseño en las PyMEs de la Comunidad Valenciana. Valencia: Universidad Politécnica de Valencia, (2003). 
[26] Otero I. Desafíos y propuestas para la implantación más efectiva de instrumentos económicos en la gestión ambiental de América Latina y el Caribe. El caso de Venezuela. CEPAL, Serie Manuales № 18, 2002. Downloaded from. www.eclac.cl/id.asp?di=11048, (12.3.2008).

[27] Hilton M. Design for Sustainable Development. Success Factors. Dublin: European Foundation for the improvement of living and working conditions, 2001.

[28] Erkko S, Melanen M, Mickwitz P. Eco-efficiency in the Finnish EMAS reports - a buzz word?. Journal of Cleaner Production 2005;13:799-813.

[29] Vives A, Corral A, Isusi I. Responsabilidad Social de la Empresa en las PyMEs de Latinoamérica. Subdepartamento de Empresa Privada y Mercados Financieros. Washington DC: Banco Interamericano de Desarrollo, 2005.

[30] Guzmán, L. Propuesta Metodológica para la Integración del Factor Ambiental en el Diseño de Productos y de Procesos, a Través del Sistema de Gestión, en la Industria del Mueble. Caso de Estudio: Sector del Mueble del Estado de Jalisco (México). Tesis Doctoral. Valencia: Universidad Politécnica de Valencia, 2005.

[31] Díaz D, Febres M, Martínez Z, Frontado, Y. Balance de la Situación Ambiental 2006. Evaluación del Sector. Downloaded from. http://www.vitalis.net//ndex4.htm, (2.11.2006)

[32] Mercado A, Testa P. Tecnología y ambiente: el desafío competitivo de la industria química y petroquímica venezolana. Caracas: Fundación Polar-CENDES, 2001.

[33] Páez T. Observatorio PYME: estudio de la pequeña y mediana empresa en Venezuela. Caracas: Corporación Andina de Fomento, 2001. 